\title{
An overview of the China National Tobacco Corporation and State Tobacco Monopoly Administration
}

\author{
Peisen He $\cdot$ Takeaki Takeuchi $\cdot$ Eiji Yano
}

Received: 7 March 2012/ Accepted: 28 May 2012/Published online: 14 June 2012

(c) The Japanese Society for Hygiene 2012

\begin{abstract}
Objectives China is facing a serious public health problem in active and passive smokers. Confronted with this, China has taken some measures to control tobacco. However, this information has not been surveyed at academic level. Our aim is to investigate information relating to tobacco controls in China.

Methods To find information relating to tobacco control, we reviewed and analysed the China National Tobacco Corporation (CNTC) and State Tobacco Monopoly Administration (STMA) mainly by systematic examination of documents made available in the University of California, San Francisco Legacy Tobacco Documents Library and China Tobacco database.

Results Eleven relevant documents met our research purpose, and 18 further relevant documents were found on the CNTC, STMA and Tobacco China database websites. As a result, 29 relevant articles were included in our analysis. We describe the CNTC and STMA's history, structure, and relation to the Chinese Government ministry and to other tobacco companies, and China's tobacco control in detail.

Conclusions The Chinese cigarette market is dominated by a state-owned monopoly, the STMA. Under the protection of the Law of the People's Republic of China on Tobacco Monopoly, the STMA controls all aspects of the tobacco industry. As far as the Chinese tobacco monopoly
\end{abstract}

P. He $\cdot$ T. Takeuchi $(\bowtie) \cdot$ E. Yano

Department of Hygiene and Public Health,

Teikyo University School of Medicine, 2-11-1 Kaga,

Itabashi-ku, Tokyo 173-8605, Japan

e-mail: takeakij@post.harvard.edu

P. $\mathrm{He}$

Department of Social Medicine,

Harbin Medical University, Harbin, China is concerned, although smoking harms people's health, restraining smoking threatens social stability and government income, which may be more serious problems for any government. China still has a long way to go in creating smoke-free environments.

Keywords China - Epidemiology $\cdot$ Public health · Smoking - Tobacco control

\section{Introduction}

The Chinese population is over 1.3 billion, constituting $23 \%$ of the world's population, of which $52.9 \%$ of adult males and $2.4 \%$ of females smoke, with $52.7 \%$ of smokers starting before the age of 20 years among young smokers aged between 20 and 34 years [1]. China is, therefore, facing a serious public health problem in active (365 million) and passive (677 million) smokers [1-3]. Smoking is an important risk factor for chronic obstructive pulmonary disease, lung cancer and tuberculosis [1], which are the second, sixth and eighth leading causes of death in China, projected to account for more than 2 million deaths before $2030[1,2]$.

Confronted with these serious tobacco problems, the Chinese Government had to reconsider the priorities between its tobacco industry interests and protecting public health. On 11 October 2005, China ratified the World Health Organization (WHO) Framework Convention on Tobacco Control (FCTC) [4, 5]. After that, China indeed adopted some specific measures for tobacco control. Meanwhile, some actions of the Chinese Government contradict their tobacco control activities.

The contradictions in China's tobacco policies reflect the inherent contradictions within the state apparatus. 
However, at present, there is no information about the Chinese tobacco industry at the scientific level. Therefore, we analysed and detailed the Chinese tobacco industry and its related operations to provide information relevant for tobacco control worldwide.

\section{Materials and methods}

We searched the online documents available from the University of California, San Francisco (UCSF) Legacy Tobacco Documents Library (LTDL) (http://legacy. library.ucsf.edu) and relevant websites including those of the China National Tobacco Company (CNTC) (http:// www.tobacco.gov.cn/), State Tobacco Monopoly Administration (STMA) and China's tobacco database (http:// www.tobaccochina.com/).

The keywords we used included "China", "China National Tobacco Company", "State Tobacco Monopoly Administration", "CNTC" and "STMA". In the LTDL, the keywords were used in the basic and advanced search. On the homepages of the CNTC, STMA and Tobacco China database, we used the keywords in their search engine. We mainly analysed documents related to the CNTC itself and its operations. Documents that were illegible, duplicated or about tobacco technology and other documents judged to have little interest to our aim were excluded.

\section{Results}

The number of documents identified by the LTDL search was 346 , and 335 documents were excluded as they failed to meet one or more inclusion criteria. So 11 relevant documents from the LTDL that met the criteria were included. Besides, 18 relevant documents were found from the CNTC, STMA and Tobacco China database websites. As a result, 29 relevant articles were included in our analysis.

\section{History of the CNTC and STMA}

The China National Tobacco Corporation is a state-owned enterprise qualified as a legal person and authorized by the Chinese Government to act in the capacity of the state tobacco monopoly. According to the Law of the People's Republic of China (PRC) on Tobacco Monopoly promulgated by the Chinese Government, the CNTC is empowered to operate all aspects of China's tobacco industry, which covers plantation of tobacco, purchase and allocation of leaf tobacco, manufacture and distribution of cigarettes, cigars and other tobacco products and import and export businesses for China's tobacco industry.
The China National Tobacco Corporation was founded in January 1982, and the head office is situated in Beijing. Under its direct leadership, provincial-level tobacco corporations have been established in all provinces, autonomous regions and municipalities, with the exception of the Xizang (Tibet) Autonomous Region. At its earlier time, with more than 300,000 staff and workers, the CNTC has over 100 cigarette factories, over 100 redrying plants and over 2,000 leaf tobacco stations and cigarette wholesale departments.

The State Tobacco Monopoly Administration was founded in 1985. It forms part of the same organization as the CNTC, but works as a governmental body for administration of the tobacco monopoly [6].

At the end of 2004, the CNTC had 33 provincial tobacco companies, 17 tobacco industrial companies, 57 cigarette industrial enterprises and over 1,000 commercial enterprises and national companies [7].

\section{CNTC and STMA structure}

The China National Tobacco Corporation and STMA are composed of 3 parts: CNTC head office, provincial-level tobacco monopoly administrations, corporations, and some accessorial departments [8]. The CNTC head office is composed of the following functional departments and offices: China Tobacco Import and Export Corporation, China Tobacco Materials Corporation, China Cigarette Marketing and Sales Corporation, China Tobacco Production, Purchasing and Sales Corporation, Science and Technology Committee and some research organizations. Beside the main structure, the CNTC still owns some accessorial departments, such as the China Tobacco Society (CTS), the Zhengzhou Tobacco Research Institute (ZTRI) and the Hefei Institute of Economics and Technology (HIET). Initiated by CNTC, the CTS, a mass academic research organization, was established and has its branches in various locations [6]. The ZTRI, situated in Zhengzhou, Henan Province, has 250 employee and 7 research units (process, analytical, flavour, machinery, computer etc.) [9]. The HIET was founded in 1989 and used as an education and research centre for tobacco scientists. The HIET has approximately 400 staff and 3,000 students, with specialties including tobacco cultivation, plant protection, process technology, analysis and diagnosis, machinery, manufacture and process automation, business administration and accounting [9].

A unique character of the Chinese tobacco industry is central planning [10]. Although this system is good for managing the huge tobacco industry system, central economic planning also has large problems. Coordination between tobacco farmers, distributors, factories and retailers is sometimes lacking or non-existent. In other 
cases, STMA polices may contradict one another. A highlevel official with the Yunnan Provincial Tobacco Monopoly Administration (YPTMA) frankly says, "Central planning has problems. Enterprises have no privilege to choose their own course; they must always follow policy." As part of the STMA, the YPTMA oversees the entire Yunnan tobacco industry, from the farmers to the factories to the exporters. The official's main complaints concern counterfeiting, overproduction and inter-provincial protectionism. Interests of a province's tobacco industry can conflict with the interests of the STMA in Beijing [10].

\section{Relation to the Chinese Government ministry}

The State Council of the PRC started to carry out organizational reform in March 2008. China Tobacco received greater attention because of its sensitive and unique character. During this reform, the Ministry of Industry and Information of the Chinese Government became responsible for the STMA, which was previously the responsibility of the National Development and Reform Commission. A professional member of the STMA staff pointed out that the STMA was the responsibility of the Ministry of Industry and Information, not merged into it, so the STMA remained a relatively independent organization, protected by the Law of the PRC on Tobacco Monopoly [11]. In this law, Article 4 of Chapter 1 states, "the department of tobacco monopoly administration under the State Council shall be responsible for the nation-wide tobacco monopoly. The departments of tobacco monopoly administration in the provinces, autonomous regions and municipalities directly under the Central Government shall be responsible for the tobacco monopoly within the areas under their respective jurisdiction, and shall be under the dual leadership of the department of tobacco monopoly administration under the State Council and the people's governments of the provinces, autonomous regions and municipalities directly under the Central Government, with the leadership of the department of tobacco monopoly administration under the State Council as the main leading authority" [12].

Four modernizations of the STMA (CNTC)

and its relations to other tobacco companies

Since its establishment, the STMA has had four specific goals: to acquire new technology, internationalize, diversify and consolidate. Typically, new technology is acquired from abroad. Foreign suppliers have been operating in China since the mid-1980s. In exchange for technology, they are offered special access to the Chinese market. The Chinese tobacco industry has made progress on STMA's second goal, internationalization; For example, China's powerhouse Yuxi Hongta Group produces several brands of American-blend cigarettes for export to Southeast Asia. Even domestic suppliers, traditionally thought to lack the technical knowhow of foreign companies, are exporting their machinery and services. A representative of Kunming Shipbuilding Equipment Company, a large producer of tobacco-related machinery, says that his company supplies manufacturers in Southeast Asia, especially Vietnam and Indonesia.

China's diversification is making headway, as well. The Yuxi Hongta Group, for example, produces more than 135 billion sticks a year. Its popular premium brand Hongtashan and medium-priced brand Hongmei are found throughout the country. Aside from cigarettes, Yuxi Hongta has branched out into other business ventures. Yuxi Hongta is involved with an automobile factory, banks, several four-star hotels, a highway, and even a hydroelectric power plant.

At the same time, consolidation is changing the playing field. According to the CNTC Economic Centre, there were 180 cigarette factories in 1997. To further improve efficiency and competitiveness, the STMA decided to reduce the number of factories [10]. China's tobacco industry is undergoing a long-term restructuring programme to consolidate resources and optimise and centralise management. Within the CNTC, a provincial tobacco corporation was established to supervise the development of the tobacco industry in each region. By the end of 2007, there were 16 provincial corporations established, which act as subsidiaries of CNTC but are independent legal entities. This will assist the CNTC in regulating and monitoring the local tobacco market, and facilitates sales across provincial borders. By 2007, the number of legal entities in the tobacco industry had fallen from around 180 to 31 [13].

From the four goals of CNTC, we can see CNTC has close relationships with other tobacco companies, especially transnational tobacco companies; For example, we can understand this situation based on the three largest tobacco companies in the world.

Philip Morris International (PMI) is the leading international tobacco company, with products sold in approximately 160 countries [14]. PMI and CNTC signed an agreement for production and marketing of Marlboro cigarettes, as well as other brands, in China beginning in 1994. The cigarettes will be produced in existing CNTC factories and will be for both domestic consumption and export. The agreement does not require any initial capital investment by PMI, but PMI will introduce technology, training and human resources expertise to the CNTC factories [15]. On 21 December 2005, the CNTC and PMI announced the establishment of a further long-term strategic cooperative partnership. Agreements provided for the licensed manufacture and sale of Marlboro cigarettes in China and the establishment of an international equity joint venture 
company in Switzerland. "In accordance with relevant provisions of the Law of the PRC on Tobacco Monopoly, Marlboro, owned by PMI, will be produced under license at CNTC's affiliate factories, and will be distributed by CNTC's official distributors nationwide in China. The international joint venture company to be established by China National Tobacco Import \& Export Group Corporation (CNTIEGC) and PMI, in which each party will hold $50 \%$ of the shares of the company, will be based in Lausanne, Switzerland. Following its establishment, this joint venture company will offer consumers a comprehensive portfolio of Chinese heritage brands globally, expand the export of tobacco products and tobacco materials from China, and explore other business development opportunities. The joint venture company will utilize both CNTC's and PMI's extensive sales and distribution infrastructure, financial resources and management experiences to develop business opportunities worldwide" [16].

British American Tobacco (BAT) is the world's second largest tobacco group by global market share, with brands sold in more than 180 markets [17]. BAT China is one of BAT's subsidiaries, and existed in China as early as 1903. At present, BAT China is the one-up international tobacco company in China and has set up agencies in many main cities. BAT products are imported and distributed by CNTC, and the main products in China are SE555, Kent and Hilton, which are popular with Chinese smokers [18].

British American Tobacco entered China when it was first established, but was forced to leave China in 1956. In the 1980s, BAT returned to China and cooperated with Wuhu Cigarette Company to produce cigarettes named "Dubao" at that time. From then on, BAT cooperated with CNTC to manufacture a series of joint-venture brands, including Coco, Huang GuoTrees, Le Fu Door and so on. In the tobacco leaf field, BAT and CNTC have been cooperating for almost 10 years [19]. In the middle of the 1990s, BAT began to "help China's agriculture" by setting up tobacco leaf base and guiding tobacco farmers to grow tobacco leaf [19]. Besides, BAT China has established a cooperation plan on tobacco leaf growth in Yunnan and Sichuan Provinces of China [18].

Japan Tobacco (JT) is the world's third largest tobacco company, with tobacco products in more than 120 countries [20]. JT and CNTC have cooperated for a long time, which is a win-win cooperation. Cooperating with Shanghai Gaoyang International Tobacco Co., JT began to make cigarettes in China from 2000 to market its own brands. JT hoped to tap the Chinese market and planed to turn out 400 million cigarettes a year in Shanghai, marketing them under its top-selling brands such as Mild Seven and Mild Seven Light [21]. Besides, JT has been cooperating with CNTC to produce Youqi and Huaying, and some Camel cigarettes are produced in the Yanji
Cigarette Factory, Jilin [22]. Besides, JT also developed the market for the Shanghai Tobacco Company in Japan through its own channels. In November 2003, Zhong Hua, Double Happiness and Golden Deer of the Shanghai Tobacco Corporation entered Japan's market through Unitobacco, which is JT's subsidiary in charge of distributing imported cigarettes. To some extent, the Shanghai Tobacco Corporation's entry into Japan means the loss of JT's domestic market share, which JT did to maintain a good relationship with CNTC and increase their market share in China in the future [22].

STMA and tobacco control

In fact, the STMA and CNTC are the same organization, with two different names obviously. It is ridiculous that the STMA is also in charge of tobacco control affairs in China besides its administrative affairs. Therefore, it is obvious that the government is the chief manager of anti-tobacco efforts, as well as the central force in developing and managing China's tobacco market. Smoking is a hard habit for the government to quit in fact, because of the state system.

After ratifying the FCTC, China indeed adopted some specific measures for tobacco control. In 2008, Beijing held the 29th Olympic Games, which was also a "smoke-free Olympics" advocated by the Chinese Government. All six mainland Olympic host cities were undertaking tobacco control initiatives with an emphasis on creating smoke-free environments. Also, in 2008, the Chinese Government funded and campaigned for a tobacco control project covering 21 provinces in central and western China, in order to improve their ability to carry out the FCTC [23]. On 23 June 2009, "Tobacco Free Cities-A Gates China Tobacco Control Partner" was started up in Qingdao City of China [24].

However, some actions of the Chinese Government contradict their tobacco control activities. Because of economic depression, the Chinese Government started to invest 4,000 billion in order to increase internal demand, 60 billion of which was spent on the tobacco industry for basic facilities aimed at tobacco growth [25, 26]. Cigarette packaging in China has changed slightly since 1 January 2009; the position of health warnings "smoking is harmful for health" has been moved from the side of the package to the frontispiece, and their area has reached 1/3 of the package. However, according to Article 11 of the FCTC, this action by China achieved the minimum requirement but has still not achieved the target of the FCTC.

\section{Discussion}

The Chinese cigarette market is dominated by a stateowned monopoly, the STMA. Under the protection of the 
Law of the PRC on Tobacco Monopoly, the STMA controls all aspects of the tobacco industry, including tobacco growing, processing, product manufacturing and distribution and also material and machinery supplies, all of which are operated through the CNTC.

The Chinese tobacco industry plays an important role in China. On the one hand, the tobacco industry employs millions of people, which is helpful to solve employment problems. At present, according to statistics from the STMA, there are 3.6 million farmers, more than 4 million tobacco retailors and 0.5 million employees in the whole tobacco industry. On the other hand, the tobacco industry could pay more than 100 billion (16 billion USD) in taxes every year [27], accounting for about $7 \%$ of Chinese Government revenue [28]. So, as far as the Chinese tobacco monopoly is concerned, although smoking harms people's health, restraining smoking would threaten social stability and government income, which may be more serious problems for any governments.

In addition, the government is under huge pressure from the tobacco industry, both domestic and foreign, which sees China's large market as the golden prize. Led by the three largest tobacco companies in the world-PMI, BAT, and JT-foreign tobacco companies and trade regulators have been pushing the government to ease market access for international brands. Especially, after China joined the WTO in 2001, it had to agree to (1) reduce its import tariff on tobacco leaf, (2) reduce the cigarette tariff, (3) eliminate the export rebate for flue-cured tobacco leaf and cigarettes and (4) eliminate the export bounty [29]. All of these agreements have made foreign cigarettes more competitive in the Chinese market, which is a good thing for tobacco companies but bad news for public health. All these pressures make the fight against smoking much more difficult.

Besides, China also has a smoking culture that imposes enormous social pressure to smoke, particularly on men. One popular saying shows the problem: "Men who don't smoke will work in vain to ascend to top of the world" [30].

Smoking has been a serious problem for humankind. Tobacco has already killed 100 million people in the 20th century, and 5.4 million deaths per year currently result from tobacco use. Owing to China's large population and number of smokers, successful tobacco control in China would be a great achievement for public health and the whole of humanity. However, for the reasons discussed above, China still has a long way to go in creating smokefree environments. Recently, academic evidence proving that tobacco damages health has increased because of the endeavours of public health practitioners and medical professionals, including pharmaceutical companies.

Although the tobacco issues in China have many conflicts, a conceivable strategy to tackle the tobacco problem in China would be to enlighten Chinese citizens about the damage that tobacco does to their health. Tobacco issues in China are not straightforward, but increasing the number of people who know about tobacco damage could become an emotional trigger towards a smoke-free nation, leading to a smoke-free world in the future.

Conflict of interest The authors declare that they have no conflict of interest

\section{References}

1. Chinese center for disease control and prevention. Global Adult Tobacco Survey (GATS) China 2010 Country Report. 2012. Available from: http://www.notc.org.cn/zyzx/lxbdc/201112/t201 11219_55830.htm. Accessed 14 May 2012.

2. Mathers CD, Loncar D. Projections of global mortality and burden of disease from 2002 to 2030. PLoS Med. 2006;3:e442.

3. Yang G. The epidemiologic investigation of the smoking behavior among the Chinese population in 2002. Chin Smok Health. 2004;62:7-18.

4. Liu BQ, Peto R, Chen ZM, Boreham J, Wu YP, Li JY, et al. Emerging tobacco hazards in China: retrospective proportional morality study of one million deaths. BMJ. 1998;317:1411-22.

5. World Health Organization. Parties to the WHO Framework Convention on Tobacco Control. 2011. Available from: http:// www.who.int/fctc/signatories_parties/en/index.html. Accessed 10 Aug 2011.

6. China National Tobacco Corporation. Brochure of China National Tobacco Corporation. Bates Number: 400108996400109016. 2011. Available from: http://legacy.library.ucsf.edu/ tid/tnn87a99. Accessed 10 Aug 2011.

7. Philip Morris International; China National Tobacco Corporation. The China National Tobacco Corporation and Philip Morris International announce the establishment of a long-term strategic cooperative partnership. 2011. Available from: http://www. philipmorrisinternational.com/pmintl/pages/eng/press/pr_20051221. asp. Accessed 10 Aug 2011.

8. STMA and CNTC. 2011. Available from: http://www.tobacco. gov.cn/html/index.html. Accessed 10 Aug 2011.

9. Anonyms. China National Tobacco Company (CNTC) State Tobacco Monopoly Administration (STMA). 2011. Bates Number: 2067470924/0932. Available from: http://legacy.library. ucsf.edu/tid/gjj34a00. Accessed 10 Aug 2011.

10. Bennett C. Biggest in the world: an overview of the STMA and the Chinese cigarette industry. 2011. Bates Number: 531624185/ 4188. 2011. Available from: http://legacy.library.ucsf.edu/tid/ kbp76a00. Accessed 10 Aug 2011.

11. Tobacco China database. China tobacco's changed or not under the reform of ministry. 2011. Available from: http://www.tobac cochina.com/news/focus/view/20084/2008422162143_298629.shtml. Accessed 10 Aug 2011.

12. Legislative affairs commission. National people's congress of the people's republic of China; State tobacco monopoly administration. Law of the people's republic of China on tobacco monopoly. Bates Number: 2065339775/9798. 2011. Available from: http:// legacy.library.ucsf.edu/tid/dns63c00. Accessed 10 Aug 2011.

13. Euromonitor International. Tobacco in China. 2011. Available from: http://www.euromonitor.com/tobacco-in-china/report. Accessed 10 Nov 2011.

14. Philip Morris International. PMI @ a glance. 2011. Available from: http://www.philipmorrisinternational.com/PMINTL/pages/ eng/ourbus/About_us.asp. Accessed 10 Aug 2011. 
15. Delman F. Executive summary: Philip Morris and the China National Tobacco Corp (CNTC) signed an agreement for the production and marketing of Marlboro cigarettes, as well as other brands, in China. Bates Number: 517390653/0654. 2011. Available from: http://legacy.library.ucsf.edu/tid/jmf97c00. Accessed 10 Aug 2011.

16. PMI and CNTC. The China National Tobacco Corporation and Philip Morris International announce the establishment of a longterm strategic cooperative partnership. 2011. Available from: http://www.philipmorrisinternational.com/pmintl/pages/eng/press/ pr_20051221.asp. Accessed 10 Aug 2011.

17. British American Tobacco. Who we are. 2011. Available from: http://www.bat.com/group/sites/uk_3mnfen.nsf/vwPagesWebLive/ DO52ADCY?opendocument\&SKN=1\&TMP=1. Accessed 10 Aug 2011.

18. British American Tobacco China online. British American Tobacco China. 2011. Available from: http://www.batchina.com/. Accessed 10 Aug 2011 (in Chinese).

19. Xinhua Net. British American Tobacco is destroying tobacco control in China. 2011. Available from: http://news.xinhuanet. com/herald/2009-01/12/content_10642519.htm. Accessed 10 Aug 2011.

20. He P, Yano E. Tobacco companies are booming despite an economic depression. Tob Induc Dis. 2009;5:9.

21. Nikkei. Japan Tobacco to Make Cigarettes in Shanghai. Bates Number: 2078786672B. 2010. Available from: http://legacy. library.ucsf.edu/tid/lne82c00. Accessed 10 Aug 2010.

22. Tobacco China database. JT in China: the advantage of being in a favored position? 2011. Available from: http://www.tobacco china.com/news/data/20046/w_3438752_617161454.htm. Accessed 10 Aug 2011 (in Chinese).

23. Tobacco China Database. Ministry of Health: quit smoking clinics are opened in 21 provinces of middle and western China.
2011. Available from: http://www.tobaccochina.com/news/control/ gn//20094/2009437359_352898.shtml. Accessed 10 Aug 2011 (in Chinese).

24. Ren J. Qing Dao city has signed to be the tobacco controlling city; smoking will be prohibited totally since 2011. 2011. Available from: http://news.tobaccochina.com/news/control/gn/ 20096/200962416122_365437.shtml. Accessed 10 Aug 2011 (in Chinese).

25. Tobacco China Database. It is difficult to control tobacco in China, and committeeman advises that the ministry of health should be in charge. 2011. Available from: http://www.tobacco china.com/news/control/gn/20093/200931115330_349022.shtml. Accessed 10 Aug 2011 (in Chinese).

26. Tobacco China Database. Using "ugly" cigarettes box to save people's health. 2011. Available from: http://www.tobacco china.com/news/control/jk/20094/200941319947_354162.shtml. Accessed 10 Aug 2011 (in Chinese).

27. Tobacco China Database. What is the biggest resistance of tobacco control in China? 2011. Available from: http://www. tobaccochina.com/news/control/opinions/20096/200961519153_ 363991.shtml. Accessed 10 Aug 2011 (in Chinese).

28. Tobacco China Database. 30 years memories of China tobacco's policy of reform and opening-up. 2011. Available online: http:// www.tobaccochina.com/news/analysis/wu/200811/2008111985219_ 332976.shtml. Accessed 10 Aug 2011 (in Chinese).

29. Hu TW, Mao Z, Ong M, Tong E, Tao M, Jiang H, et al. China at the crossroads: the economics of tobacco and health. Tob Control. 2006;15(Suppl 1):i37-41.

30. Walker B. China tobacco: A tough habit to break. 2011. Available from: http://globaltechforum.eiu.com/index.asp?layout=rich_ story\&doc_id $=11334 \&$ title $=$ china + tobacco $\% 3 \mathrm{~A}+\mathrm{A}+$ tough + habit + to + break\&channelid=4\&categoryid=30. Accessed 10 Aug 2011 . 